\title{
Comunicação
}

[Communication]

\section{Proteinograma sérico de veados-catingueiro (Mazama gouazoubira) criados em cativeiro obtido por eletroforese em gel de agarose e de poliacrilamida (SDS PAGE)}

\author{
[Serum protein concentrations of captive brown brocket deer (Mazama gouazoubira) determined by means of \\ agarosis and sodium dodecyl sulphate-polyacrylamide (SDS-PAGE) gel electrophoresis] \\ A.M. Santana ${ }^{1}$, J.J. Fagliari ${ }^{2 *}$, C.M.S. Camargo ${ }^{1}$, A.E. Santana ${ }^{2}$, \\ J.M.B. Duarte ${ }^{2}$, P.R.L. Silva ${ }^{3}$ \\ ${ }^{1}$ Aluno de pós-graduação - FCAV-UNESP - Jaboticabal, SP \\ ${ }^{2}$ Faculdade de Ciências Agrárias e Veterinárias - UNESP \\ Via de Acesso Prof. Paulo Donato Castellane, s/n \\ 14884-900 - Jaboticabal, SP \\ ${ }^{3}$ Aluno de graduação - FCAV-UNESP - Jaboticabal, SP
}

O veado-catingueiro é um cervídeo com peso em torno de $18 \mathrm{~kg}$, altura média de $0,50 \mathrm{~m}$, geralmente apresenta pelagem de coloração variável, de cinzaescuro a marrom-avermelhado (Duarte, 1996). Habita regiões de cerrado, do sul do Amazonas até o norte da Argentina (Ávila-Pires, 1959; Jungius, 1976; Jackson et al., 1980). É capaz de ocupar áreas degradadas, contanto que tenham pequenos capões de mata ou cerrado para se abrigarem durante o dia (Duarte, 1996). A população é relativamente grande, tanto em vida livre como em cativeiro, mas a literatura é escassa em trabalhos que relatam os valores de constituintes do soro sangüíneo de animais normais, especialmente do proteinograma.

A avaliação dos teores de proteína total e de suas frações propicia subsídios para adequada interpretação do estado de hidratação, bem como de inflamação, infecção, doenças imunomediadas e alteração na síntese protéica.

O fracionamento eletroforético representa um dos mais confiáveis meios de identificação de proteínas sangüíneas (Kaneko et al., 1997). As técnicas de eletroforese mais utilizadas em medicina veterinária têm como matrizes fitas de acetato de celulose (Fagliari et al., 1991) ou filmes de agarose (Keay e Doxey, 1982), as quais representam valor limitado porque permitem o fracionamento de cinco a sete

Recebido em 5 de dezembro de 2007

Aceito em 30 de outubro de 2008

* Autor para correspondência (corresponding author)

E-mail: fagliari@fcav.unesp.br grupos de proteínas. Contudo, é a técnica mais facilmente disponível na rotina laboratorial. Gordon (1995) relatou que a técnica de eletroforese em gel de poliacrilamida contendo dodecil sulfato de sódio (SDS-PAGE) é relativamente simples e de baixo custo, possibilitando a visualização de concentrações séricas extremamente baixas e a identificação de 15 a 20 proteínas. O emprego dessa técnica em medicina veterinária pode ser útil na avaliação da imunidade passiva e da cinética das proteínas de fase aguda na resposta inflamatória, facilitando a definição do diagnóstico de diversas doenças animais (Fagliari et al., 2003; Fagliari et al., 2006).

O objetivo deste estudo foi estabelecer o proteinograma sérico de veados-catingueiro, com o uso das técnicas de eletroforese em gel de agarose e em gel de poliacrilamida com dodecil sulfato de sódio (SDS-PAGE), de modo a propiciar informações que contribuam na interpretação de resultados de exames de laboratório e, conseqüentemente, facilitem o diagnóstico de enfermidades nessa espécie animal.

Foram examinados 10 veados-catingueiro (quatro machos e seis fêmeas) adultos, mantidos em baias individuais e protegidos de barulho, localizados no Núcleo de Pesquisa e Conservação de Cervídeos da UNESP, campus de Jaboticabal. O experimento foi 
realizado de julho de 2003 a junho de 2004. Segundo dados da estação agroclimatológica do Departamento de Ciências Exatas - UNESP, campus de Jaboticabal, a temperatura atmosférica média durante inverno, primavera, verão e outono em que foi realizado o experimento foi, respectivamente, de 20,6;24,3; 23,7 e $19,9^{\circ} \mathrm{C}$. Nesse mesmo período, os valores de insolação média foram, respectivamente, de 260,$2 ; 224,8 ; 218,1$ e $207,1 \mathrm{~h}$, sendo que, no verão e no outono, houve menor luminosidade (média de 10,7h) e, no inverno e na primavera mais luminosidade (média de 13,3h). Os animais receberam dieta à base de ração comercial para eqüinos $^{1}$ e de forrageira verde (soja perene, alfafa, amora), à vontade.

Para realização do proteinograma, foram colhidas amostras de sangue, mensalmente, ao longo de doze meses, por venopunção jugular, em tubos adequados ao sistema de coleta a vácuo, sem anticoagulante, adequadamente armazenados em isopor com gelo. Após a retração do coágulo, as amostras de soro foram submetidas à centrifugação a 2.000 rotações por minuto, durante cinco minutos, e estocadas à temperatura de $18^{\circ} \mathrm{C}$ negativos, até o momento das análises laboratoriais. Para realização da coleta, os animais foram contidos fisicamente por não mais que dois minutos.

A concentração sérica de proteína total foi determinada pelo método do biureto, utilizando-se conjunto de reagentes comercial ${ }^{2}$ e leitura em espectrofotômetro (Labquest) ${ }^{2}$. O proteinograma sérico foi obtido tanto em matriz de gel de agarose $(\text { Celmgel })^{3}$ quanto em SDS-PAGE. O fracionamento eletroforético das proteínas das amostras do soro sangüíneo em gel de agarose ${ }^{3}$ foi realizado utilizando-se técnica empregada por Fagliari et al. (1991). A leitura das frações protéicas foi realizada em densitômetro ${ }^{4}$, em comprimento de onda de $520 \mathrm{~nm}$. Para o fracionamento eletroforético das proteínas em SDS-PAGE, utilizou-se a técnica proposta por Weber e Osborn (1969). Os pesos moleculares e as concentrações das frações protéicas foram determinados mediante densitometria. Para a identificação das proteínas, foram utilizados marcadores com pesos

${ }^{1}$ Passeio/Purina ${ }^{\circledR}$ - São Paulo, Brasil.

${ }^{2}$ Labteste Diagnóstica S.A. - Lagoa Santa, Brasil.

${ }^{3}$ Cia. Equipadora de Laboratórios Modernos - Barueri, Brasil. ${ }^{4}$ Shimadzu CS-9301 - Shimadzu Corporation - Tóquio, Japão. moleculares de $29 \mathrm{kD}, 45 \mathrm{kD}, 66 \mathrm{kD}, 94 \mathrm{kD}$ e $205 \mathrm{kD}$. As proteínas purificadas foram haptoglobina, ceruloplasmina, transferrina, antitripsina e imunoglobulina G. Para a avaliação densitométrica das bandas protéicas, foram confeccionadas curvas de referência a partir da leitura do marcador padrão. Para as análises estatísticas, utilizou-se o pacote estatístico SAS (User's..., 1995). Quando houve diferenças significativas entre os proteinogramas, aplicou-se $\mathrm{o}$ teste Tukey $(\mathrm{P}<0,05)$ para a comparação das médias.

Os teores séricos de proteína total foram similares quando comparados entre as estações do ano e entre sexos, variaram de $7,9 \pm 0,9 \mathrm{~g} / \mathrm{dl}$ (outono) a $8,42 \pm 0,69 \mathrm{~g} / \mathrm{dl}$ (primavera) e de $8,18 \pm 0,81 \mathrm{~g} / \mathrm{dl}$ (fêmeas) a $8,22 \pm 0,8 \mathrm{~g} / \mathrm{dl}$ (machos), respectivamente.

O proteinograma em gel de agarose revelou a presença de quatro frações protéicas: albumina, alfaglobulina, betaglobulina e gamaglobulina. As concentrações séricas de alfa, beta e gamaglobulina não foram influenciadas pela estação do ano. Já as concentrações séricas de albumina diferiram significativamente entre a primavera e o verão (Tab. 1), com valores mais elevados na primeira em relação à segunda estação. Essa diferença não foi observada quando se utilizou SDS-PAGE. Nesse caso, tais diferenças podem ter ocorrido devido a variações nas técnicas utilizadas. Apenas as concentrações séricas de albumina e alfaglobulina foram influenciadas pelo sexo. As fêmeas apresentaram maiores teores de albumina, e os machos maiores concentrações de alfaglobulina (Tab. 2).

O SDS-PAGE possibilitou a detecção de 34 proteínas, cujos pesos moleculares variaram de $18 \mathrm{kD}$ a $165 \mathrm{kD}$. A partir da metodologia utilizada, foi possível a identificação nominal de 10 dessas proteínas: imunoglobulina A $(\mathrm{PM}=142 \mathrm{kD})$, ceruloplasmina $(\mathrm{PM}=115 \mathrm{kD})$, hemopexina $(\mathrm{PM}=$ $83 \mathrm{kD})$, transferrina $(\mathrm{PM}=75 \mathrm{kD})$, albumina $(\mathrm{PM}=$ 66kD), imunoglobulina $\mathrm{G}$ de cadeia pesada ( $\mathrm{PM}=$ $60 \mathrm{kD})$, haptoglobina $(\mathrm{PM}=45 \mathrm{kD})$, glicoproteína ácida $(\mathrm{PM}=42 \mathrm{kD})$, imunoglobulina $\mathrm{G}$ de cadeia leve $(\mathrm{PM}=32 \mathrm{kD})$ e hemoglobina $(\mathrm{PM}=18 \mathrm{kD})$. As demais proteínas foram identificadas apenas com base nos respectivos pesos moleculares. Em relação às estações do ano, verificou-se que os valores de 11 proteínas foram significativamente diferentes entre pelo menos duas estações (Tab. 3). 
Tabela 1. Média e desvio-padrão das concentrações séricas de albumina, alfaglobulina, betaglobulina e gamaglobulina, de 10 veados-catingueiro (Mazama gouazoubira) criados em cativeiro, identificadas no proteinograma obtido em gel de agarose, nas diferentes estações do ano

\begin{tabular}{lcccc}
\hline Proteína $(\mathrm{g} / \mathrm{dl})$ & Inverno & Pimavera & Verão & Outono \\
\hline Proteína total & $8,22 \pm 0,68 \mathrm{a}$ & $8,42 \pm 0,69 \mathrm{a}$ & $8,21 \pm 0,85 \mathrm{a}$ & $7,90 \pm 0,90 \mathrm{a}$ \\
Albumina & $3,96 \pm 0,49 \mathrm{ab}$ & $4,15 \pm 0,35 \mathrm{a}$ & $3,64 \pm 0,62 \mathrm{~b}$ & $3,93 \pm 0,32 \mathrm{ab}$ \\
Alfaglobulina & $0,42 \pm 0,16 \mathrm{a}$ & $0,42 \pm 0,10 \mathrm{a}$ & $0,54 \pm 0,23 \mathrm{a}$ & $0,46 \pm 0,17 \mathrm{a}$ \\
Betaglobulina & $1,82 \pm 0,18 \mathrm{a}$ & $1,73 \pm 0,21 \mathrm{a}$ & $1,88 \pm 0,25 \mathrm{a}$ & $1,87 \pm 0,66 \mathrm{a}$ \\
Gamaglobulina & $1,91 \pm 0,35 \mathrm{a}$ & $1,95 \pm 0,27 \mathrm{a}$ & $2,12 \pm 0,98 \mathrm{a}$ & $1,99 \pm 0,76 \mathrm{a}$ \\
\hline
\end{tabular}

Médias de uma mesma linha seguidas por letras distintas diferem entre si pelo teste Tukey $(\mathrm{P}<0,05)$.

Tabela 2. Média e desvio-padrão (DP) das concentrações séricas de albumina, alfaglobulina, betaglobulina e gamaglobulina, de 10 veados-catingueiro (Mazama gouazoubira), machos e fêmeas, criados em cativeiro, identificadas no proteinograma obtido em gel de agarose

\begin{tabular}{lcc}
\hline Proteína & Fêmea $(\mathrm{n}=6)$ & Macho $(\mathrm{n}=4)$ \\
\hline Proteína total & $8,18 \pm 0,81 \mathrm{a}$ & $8,22 \pm 0,80 \mathrm{a}$ \\
Albumina & $4,05 \pm 0,50 \mathrm{a}$ & $3,75 \pm 0,43 \mathrm{~b}$ \\
Alfaglobulina & $0,39 \pm 0,20 \mathrm{a}$ & $0,53 \pm 0,11 \mathrm{~b}$ \\
Betaglobulina & $1,88 \pm 0,50 \mathrm{a}$ & $1,77 \pm 0,23 \mathrm{a}$ \\
Gamaglobulina & $1,90 \pm 0,62 \mathrm{a}$ & $2,11 \pm 0,75 \mathrm{a}$ \\
\hline
\end{tabular}

Médias de uma mesma linha seguidas por letras distintas diferem entre si pelo teste Tukey $(\mathrm{P}<0,05)$.

Tabela 3. Proteína total sérica (g/dl), pesos moleculares (PM; Kilodálton, kD) e média e desvio-padrão dos teores séricos $(\mathrm{mg} / \mathrm{dl})$ de proteínas de veados-catingueiro (Mazama gouazoubira) criados em cativeiro, obtidas em gel de poliacrilamida (SDS-PAGE), nas diferentes estações do ano

\begin{tabular}{|c|c|c|c|c|c|}
\hline Proteína & PM & Inverno & Primavera & Verão & Outono \\
\hline Proteína total & & $8,22 \pm 0,68 \mathrm{a}$ & $8,42 \pm 0,69 a$ & $8,21 \pm 0,85 a$ & $7,90 \pm 0,90 \mathrm{a}$ \\
\hline NI & & $0,6 \pm 0 \mathrm{a}$ & $1,29 \pm 2,4 a$ & $1 \pm 0 \mathrm{a}$ & - \\
\hline NI & 165 & $9,75 \pm 9,9 \mathrm{a}$ & $8,57 \pm 7,09 a$ & $9,74 \pm 5,38 \mathrm{a}$ & $7,92 \pm 8,11 \mathrm{a}$ \\
\hline NI & & - & $1 \pm 0$ & - & - \\
\hline NI & 158 & $44,7 \pm 33,6 a$ & $24,02 \pm 31,6 b$ & $18,22 \pm 10,41 \mathrm{~b}$ & $18,48 \pm 10,46 b$ \\
\hline NI & & $4 \pm 0 \mathrm{a}$ & $5,89 \pm 0 \mathrm{a}$ & $4,49 \pm 5,17 a$ & $8 \pm 9,11 \mathrm{a}$ \\
\hline NI & & - & $5,8 \pm 1,41 \mathrm{a}$ & $6,18 \pm 9,09 \mathrm{a}$ & $5,18 \pm 4,71 \mathrm{a}$ \\
\hline NI & 150 & $70,91 \pm 16,68 \mathrm{a}$ & $59,66 \pm 36,25 \mathrm{ab}$ & $40,59 \pm 13,85 b$ & $33,96 \pm 37,08 b$ \\
\hline NI & & - & $11,83 \pm 7,55 \mathrm{a}$ & $9,25 \pm 7,95 \mathrm{ab}$ & $5,63 \pm 4,43 b$ \\
\hline $\operatorname{Ig} \mathrm{A}$ & 142 & $78,56 \pm 35,25 a$ & $69,89 \pm 30,2 a$ & $47,27 \pm 44,4 \mathrm{a}$ & $53,33 \pm 42,89 a$ \\
\hline NI & 122 & $55,4 \pm 18,05 \mathrm{a}$ & $33,15 \pm 16,44 b$ & $22,56 \pm 25,71 b$ & $17,33 \pm 14,24 b$ \\
\hline Ceruloplasmina & 115 & $10 \pm 0 \mathrm{~b}$ & $9,06 \pm 8,73 \mathrm{~b}$ & $48,16 \pm 25,94 \mathrm{ab}$ & $68,52 \pm 30,94 a$ \\
\hline NI & 110 & $20,4 \pm 121,97 a$ & $90,57 \pm 8,58 \mathrm{a}$ & $48,16 \pm 13,44 a$ & $68,52 \pm 5,53 a$ \\
\hline NI & & - & $4,5 \pm 0 \mathrm{a}$ & $7,47 \pm 16,63 a$ & $3,12 \pm 1,27 \mathrm{a}$ \\
\hline NI & 101 & $54,44 \pm 16,02 \mathrm{a}$ & $42,20 \pm 20,53 a$ & $42,69 \pm 138,12 a$ & $38,78 \pm 11,97 \mathrm{a}$ \\
\hline Hemopexina & 83 & $291 \pm 133 a$ & $221 \pm 138 a$ & $244 \pm 109 a$ & $261 \pm 142 a$ \\
\hline Transferrina & 75 & $19,5 \pm 345,42 \mathrm{a}$ & $17,93 \pm 14,71 \mathrm{~b}$ & $26,45 \pm 12,98 b$ & $18,02 \pm 7,74 b$ \\
\hline Albumina & 66 & $6433 \pm 2540 \mathrm{ab}$ & $5841 \pm 669 a$ & $5209 \pm 482 \mathrm{ab}$ & $5001 \pm 297 b$ \\
\hline $\mathrm{NI}$ & & $4,33 \pm 0$ & - & - & - \\
\hline NI & & $107,5 \pm 46,03 a$ & $68,08 \pm 25,45 \mathrm{a}$ & $53,0 \pm 0 \mathrm{a}$ & $80,0 \pm 0 \mathrm{a}$ \\
\hline IgG cadeia pesada & 60 & $558 \pm 214 b$ & $1211 \pm 598 \mathrm{a}$ & $1635 \pm 833 a$ & $1493 \pm 602 a$ \\
\hline NI & & $39,50 \pm 4,47 a$ & $4,08 \pm 0 b$ & $3,25 \pm 1,15 b$ & - \\
\hline NI & 53 & $9 \pm 31,62 \mathrm{a}$ & $27,79 \pm 29,71 \mathrm{a}$ & $9,02 \pm 10,57 \mathrm{a}$ & $20,58 \pm 5,77 a$ \\
\hline Haptoglobulina & 45 & $51,33 \pm 0 \mathrm{a}$ & $42,18 \pm 258,2 \mathrm{ab}$ & $27,65 \pm 1046 b$ & $49,81 \pm 0 \mathrm{a}$ \\
\hline Glicoproteína ácida & 42 & $30,5 \pm 5,66 \mathrm{a}$ & $59 \pm 29,28 \mathrm{a}$ & $22,32 \pm 29,83 a$ & $32,25 \pm 28,12 \mathrm{a}$ \\
\hline NI & 40 & $78,2 \pm 0 \mathrm{a}$ & $60,27 \pm 1,07 \mathrm{a}$ & $28,63 \pm 0 b$ & $19,31 \pm 0,56 b$ \\
\hline NI & 38 & $29,6 \pm 27,37 a$ & $46,42 \pm 7,21 \mathrm{a}$ & $36,42 \pm 7,08 \mathrm{a}$ & $51,68 \pm 5,02 \mathrm{a}$ \\
\hline NI & 35 & $9 \pm 0 \mathrm{a}$ & $12,67 \pm 0 \mathrm{a}$ & - & $24 \pm 0 \mathrm{a}$ \\
\hline NI & 34 & $19,29 \pm 0 a$ & $18,25 \pm 12,43 \mathrm{a}$ & $15,17 \pm 8,21 \mathrm{a}$ & $21,64 \pm 11,65 a$ \\
\hline IgG cadeia leve & 32 & $357 \pm 54 a$ & $446 \pm 7 a$ & $489 \pm 4 a$ & $470 \pm 8 \mathrm{a}$ \\
\hline NI & & - & $21.0 \pm 2.59$ & - & - \\
\hline NI & 30 & $242 \pm 48 \mathrm{a}$ & $220 \pm 25 a$ & $187 \pm 32 \mathrm{a}$ & $188 \pm 23 a$ \\
\hline NI & & $14,33 \pm 48,01 \mathrm{a}$ & $6,5 \pm 3,05 a$ & $9 \pm 3,73 a$ & $41 \pm 1,87 a$ \\
\hline Hemoglobina & 18 & $39,22 \pm 437.87 \mathrm{a}$ & $71,19 \pm 48,87 \mathrm{a}$ & $66,11 \pm 31,35 \mathrm{a}$ & $125 \pm 99 a$ \\
\hline NI & & - & $17,0 \pm 32,73$ & - & - \\
\hline
\end{tabular}

Médias de uma mesma linha seguidas por letras distintas diferem entre si pelo teste Tukey $(\mathrm{P}<0,05)$.

$\mathrm{NI}=$ não identificada nominalmente. 
Concluindo, em razão de os 10 animais serem mantidos no mesmo espaço físico e submetidos ao mesmo sistema de manejo, inclusive nutricional, considera-se que tais diferenças sejam decorrentes de variações próprias da espécie, ao longo do ano. Assim, é possível que os resultados apresentados sejam úteis na avaliação das concentrações das proteínas do soro sangüíneo de veados-catingueiro e, conseqüentemente, no diagnóstico e prognóstico de doenças inflamatórias, nutricionais e imunomediadas.

Palavras-chave: veado-catingueiro, proteinograma, eletroforese, SDS-PAGE

\begin{abstract}
The serum protein concentrations of brown brocket deer (Mazama gouazoubira) obtained by agarosis gel and sodium dodecyl sulphate-polyacrylamide (SDS-PAGE) gel were determined from blood samples of ten adult healthy animals (six females and four males), monthly collected in the morning, during 12 months. The animals, maintained in individual stable and protected from noise, received ad libitum a diet of comercial ration and green roughage. Serum protein concentrations in agarosis gel revealed the presence of four protein fractions: albumin, alphaglobulin, betaglobulin, and gammaglobulin. Only serum concentrations of albumin were influenced by season, being values in spring higher than values in summer $(4.15 \times 3.64 \mathrm{~g} / \mathrm{dl})$. Serum concentrations of albumin $(4.05 \times 3.75 \mathrm{~g} / \mathrm{dl})$ were higher for female and alphaglobulin $(0.39 \times 0.53 \mathrm{~g} / \mathrm{dl})$ werehigher for males. Results showed 34 proteins with molecular weights ranging from $18 \mathrm{kD}$ to $165 \mathrm{kD}$. Significant differences between at least two seasons were found on values of 11 proteins. In conclusion, on account of the 10 animals been maintained in the same physical space and submitted to the same handling system, physiological variations, which are characteristic of this species, can be apointed as the reason of these differences.
\end{abstract}

Keywords: brown brocket deer, serum protein concentrations, electrophoresis, SDS-PAGE

\section{AGRADECIMENTO}

À FAPESP, pelo auxilio financeiro concedido.

\section{REFERÊNCIAS BIBLIOGRÁFICAS}

ÁVILA-PIRES, F.D. As formas sulamericanas do veado-virá. An. Acad. Bras. Cien., v.31, p.547-556, 1959.

DUARTE, J.M.B. Guia de identificação dos cervídeos brasileiros. Jaboticabal: FUNEP, 1996. 8p.

FAGLIARI, J.J.; OKUBA, H.T.; PASSIPIERI, M. et al. Proteinograma sérico de bovinos da raça Guzerá de diferentes idades. Arq. Bras. Med. Vet. Zootec., v.34, p.39-60, 1991.

FAGLIARI, J.J.; WEISS, D.J.; McCLENAHAN, D. et al. Serum protein concentrations in calves with experimentally induced pneumonic pasteurellosis. Arq. Bras. Med. Vet. Zootec., v.55, p.383-387, 2003.

FAGLIARI, J.J.; RIZOLLI, F.W.; SILVA, S.L. et al. Proteinograma sérico de bezerros recém-nascidos da raça Holandesa obtido por eletroforese em gel de poliacrilamida. Arq. Bras. Med. Vet. Zootec., v.58, p.450-453, 2006.
GORDON, J.N. Electrophoresis of proteins in polyacrylamide and starch gels. New York: Elsever, 1995. 213p.

JACKSON, J.; LANDA, P.; LANGGUTH, A. Pampas deer in Uruguai. Oryx, v.15, p.267-272, 1980.

JUNGIUS, H. Status and distribution of threatened deer species in South America. In: JACKSON, J. (Ed). World Wildlife Yearbook 1975-76. New York: World Wildlife Fund, 1976. p.203-221.

KANEKO, J.J.; HARVEY, J.W.; BRUSS, M.L. Clinical biochemistry of domestic animals. 5ed. New York: Academic, 1997. 932p.

KEAY, G.; DOXEY, D.L. Speciescharacteristics of serumproteins demonstrated after agarose gel electrophoresis. Vet. Res. Commum., n.5, p.263-270, 1982.

USER'S guide: statistical analysis system. version 6.2. Cary: SAS Institute, 1995.

WEBER, K.; OSBORN, M. The reliability of molecular weight determinations by dodecyl sulfatepolyacrylamide gel electrophoresis. J. Biol. Chem., v.214, p.4406-4412, 1969. 